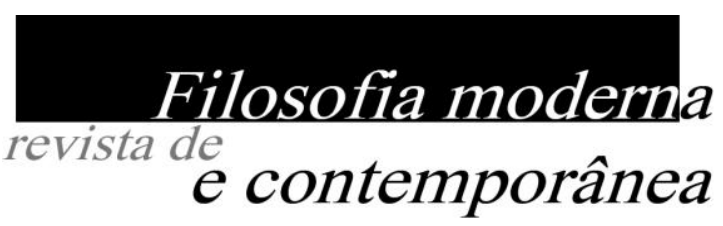

\title{
Normatividade e Determinação nas Investigações Filosóficas ${ }^{1}$ \\ Giovane Rodrigues $^{2}$
}

Resumo: Boa parte dos esforços empreendidos por Wittgenstein em suas Investigações Filosóficas se orientam no sentido contrário à ideia de que a normatividade da lógica atua sobre os falantes de uma língua como uma força compulsora. A lógica e suas regras seriam, segundo essa concepção, a maquinaria subjacente à nossa linguagem: sua condição de possibilidade e, ao mesmo tempo, nosso instrumento de controle sobre os usos linguísticos. Retomamos o método wittgensteiniano para avaliar a função normativa de proposições gramaticais em casos particulares, visando mostrar os excessos mais comuns da filosofia da lógica. Daí resulta a visão minimalista que Wittgenstein tem da lógica, da gramática e do conceito de "normatividade": a lógica exibe perspicuamente a linguagem ordinária justamente porque pretende apresentar-se como o parâmetro de correções para os próximos usos.

Abstract: A great deal of Wittgenstein's efforts in his major work, the Philosophical Investigations, is oriented against the idea that the normativity of logic is a compelling force over the speakers of a language. According to this conception, the logic and its rules are something like the machinery underlying our language, being at the same time the condition of possibility for language as well as the way by which we assess the correct linguistic uses. We apply the Wittgensteinian method by way of examining the normative function of grammatical propositions in particular cases. The primary aim of this exam is to show the most usual missteps of the philosophy of logic. This way we expect to expound Wittgenstein's minimalist vision of what logic, grammar and normativity are: logic exhibits ordinary language with the purpose of presenting itself as the parameter by which the correction of all further uses should be assessed.

\footnotetext{
${ }^{1}$ As referências às obras de Wittgenstein se darão a partir das seguintes abreviações: PU Philosophische Untersuchungen [Investigações Filosóficas]; BGM - Bermerkungen über de Grundlagen der Mathematik [Observações sobre os Fundamentos da Matemática]; LFM Lectures on the Foundations of Mathematics (1939) [Lições sobre os Fundamentos da Matemática (1939)].

2 Mestre em Filosofia pela Universidade de São Paulo - USP.
} 
No uso que Ludwig Wittgenstein faz do conceito de "gramática" residem alguns dos aspectos mais marcantes de sua filosofia tardia. Poderíamos tomá-lo, numa palavra, como designando um conjunto de regras que orientam nossos usos linguísticos. Mas também: como o sucedâneo do conceito de "lógica". Entender como Wittgenstein apresenta o conceito de "gramática" - em especial, o modo como regras gramaticais operam no interior do uso linguístico — nos dá acesso a algumas das suas mais profícuas reflexões em torno da relação entre lógica e linguagem, bem como em torno da pergunta, decisiva para boa parte da filosofia do século XX: "o que é seguir uma regra?".

1.

Eis a perspectiva segundo a qual abordaremos esse tema geral: a normatividade caracteriza o conceito de gramática. Mas o que significa dizer que "a gramática é normativa"’? Antes de qualquer coisa, será útil descartar uma possível interpretação dessa afirmação. Alguém poderia dizer: ela é uma tese a respeito da lógica de nossa linguagem.

3 No período de escrita das Investigações Filosóficas (1937-1945), o conceito de "normatividade" é conectado sobretudo à matemática. Wittgenstein diz, emblematicamente, "a matemática é normativa" (BGM VII §61, p. 425) e também: "a matemática forma uma teia de normas" (BGM VII §67; ou, em outro contexto: MS 127, p. 135); (ver também BGM VI §9; MS 123, p. 49v). Mostraremos que de modo geral isso também se aplica à lógica. De resto, Wittgenstein ele mesmo deixou clara essa aplicação do conceito de "normatividade" nos últimos manuscritos. Ver, por exemplo, MS 176, p. 9v (publicado nas Observações sobre as Cores, Parte I, §32): Sätze werden oft an der Grenze von Logik und Empirie gebraucht, (so) daß ihr Sinn über die Grenze hin und her wechselt, und sie bald als Ausdruck einer Norm, bald als Ausdruck einer Erfahrung gelten. Ver também Über Gewissheit §§167, 321.

138

\section{Revista de Filosofia Moderna e Contemporanea}

Brasília, nº 1, ano 1, 2013. 
Bem, aquela afirmação é muito menos que uma tese. Aqui se diz apenas que a gramática (tanto quanto a lógica e, nesse caso, tanto quanto a matemática) consiste em regras. Ou normas. E essa trivialidade é o que nos permite dizer: a lógica é feita de normas, por isso ela é normativa (por isso ela normatiza; ou ainda: a lógica consiste em regras, por isso ela regula). Isso são tautologias, afirmações vazias, já que dizer "esta proposição tem função normativa" é, a partir do que foi dito, o mesmo que dizer "esta proposição tem função lógica (ou gramatical)". Dito de outra maneira: ela não nos diz (nem pretende dizer) nada a respeito da natureza da lógica. Apenas a coloca em relação com mais um conceito (o de "normatividade").

Mas ligar os conceitos de gramática e normatividade não nos deixa simplesmente no campo das trivialidades. Se não, vejamos. Wittgenstein é claro ao dizer que "normativo" se opõe a "descritivo" (MS 124, p.76) ${ }^{4}$. Bem, dizer que a lógica não é constituída a partir da descrição de coisa alguma é um passo importante para que tenhamos mais clareza em relação ao que iremos dizer sobre o conceito de lógica. Em especial, porque assim nós afastamos a ideia de que proposições lógicas descrevem a “logical machinery” (LFM, p. 194) operando por trás de nossos símbolos, ou a estrutura da linguagem. A partir desse primeiro passo, estamos preparados para este outro: embora a lógica não nos apresente um domínio de fatos especiais, ela ainda assim nos diz algo. É nesse sentido que Wittgenstein diz:

Os passos que não se colocam em dúvida são inferências lógicas. Mas não é porque eles "correspondem certamente à verdade"

\footnotetext{
${ }^{4}$ Nessa passagem Wittgenstein menciona um "jogo normativo - em oposição a um [jogo] descritivo". Essa passagem deveria ter sido impressa em BGM V §17. Estranhamente, ela é a única sentença que, estando presente no manuscrito 124, foi excluída desta seção das Observações.
} 
que nós não os colocamos em dúvida — ou algo semelhante mas isso é, na verdade, o que chamamos "pensar", "falar", "inferir". 5 (BGM I, \156).

A lógica pode então ser chamada de normativa na medida em que ela nos mostra como usamos as palavras de nossa linguagem. Uma proposição gramatical (ou lógica) se oferece como o modelo de como devemos usar certas palavras de nossa linguagem. Mas não é como se essas prescrições pairassem no ar, como se elas fossem completamente arbitrárias. A lógica, diz Wittgenstein, “mostra aquilo que nós compreendemos por 'sentença' e por ‘linguagem"” (BGM I \$134, p. 90). E, além disso, ela mostra “como os homens pensam e também o que os homens chamam de "pensar"' (BGM I \$131, p. 89). Vê-se, assim, que a função normativa da lógica está intrinsecamente associada a verbos como "mostrar", "apresentar", "exibir". Quer dizer: “exibir”, “apresentar”, “mostrar” o funcionamento da linguagem é justamente o propósito da lógica ${ }^{6}$. E, num sentido qualificado, trata-se também de "descrição". Mas não de leis lógicas, e sim de usos linguísticos. Quer dizer, faz pouco sentido, aos olhos de Wittgenstein, apresentar a lógica como Frank P. Ramsey o faz — como se fosse preciso escavar os fenômenos em busca das leis lógicas que, sem que saibamos exatamente como, regem

\footnotetext{
${ }^{3}$ Die Schritte, welche man nicht in Frage zieht, sind logische Schlüsse. Aber man zieht sie nicht darum nicht in Frage, weil sie 'sicher der Wahrheit entsprechen' - oder dergl. - sondern, dies ist es eben, was man 'Denken', 'Sprechen', 'Schließen', 'Argumentieren', nennt.

${ }^{4}$ Uma argumentação mais completa acerca dessa afirmação é oferecida em meu artigo "Jogos de linguagem sem regras", a ser publicado subsequentemente. Seguimos Wittgenstein ao mostrar que o que normalmente chamamos de regra deve ser um símbolo explícito no interior do jogo de linguagem que ela regula. Decorre disso a caracterização mais geral da lógica a partir de sua função: chamamos de "lógica" a apresentação (gramatical) do funcionamento de um jogo de linguagem.
}

140

\section{Revista de Filosofia Moderna e Contemporânea Brasília, no 1, ano 1, 2013.}


nossos usos da linguagem (cf. PU \81). Como se, independente da ação dos homens, elas pudessem determinar o sentido de nossas expressões. Como se houvesse algo que precedesse o uso da linguagem e que extrairia sua normatividade justamente dessa precedência.

Nas Investigações Filosóficas e nas Observações Sobre os Fundamentos da Matemática, Wittgenstein se esforça para mostrar que a lógica não é algo independente dos proferimentos de prescrições ou proscrições sobre como usar símbolos. Ela não é, por exemplo, uma estrutura a priori que subjaz aos usos linguísticos. Até porque essa sugestão de um subsolo da linguagem está em conflito com este que é um dos mais marcantes Leitmotive wittgensteinianos: o que está oculto não interessa à filosofia. Se não vemos regras operando num jogo de linguagem é simplesmente perigoso dizer que elas estão "pressupostas". Isso poderia sugerir que algum tipo de "presença lógica" (ou transcendental) é necessária para que possamos articular uma proposição com sentido. Como veremos em detalhe, o recurso ao conceito de normatividade pretende nos afastar dessa lógica cheia de pressupostos e nos devolver àquilo que nós vemos no uso de regras. Mas, antes, precisamos delinear melhor os mal-entendidos que esse uso do conceito de normatividade quer pôr de lado.

\section{2.}

Em determinado momento das Investigações, Wittgenstein se vê às voltas com o seguinte problema: parece razoável dizer que, uma vez estando dadas as regras (de um jogo, de um cálculo, de um modelo cinemático), os passos a serem dados já estão todos determinados (no mesmo sentido em que os 
movimentos de uma máquina estão todos determinados uma vez que tenhamos um projeto completo de seus mecanismos [cf. PU \$193], ou em que o movimento de um trem está determinado pelos trilhos sobre os quais ele desliza). No mesmo sentido, expressões como die Regel bestimmt, was ich aufjeder Stufe zu schreiben habe (MS 1248 ${ }^{7}$ p. 201), ou die Übergänge sind eigentlich schon gemacht (PU \$219) parecem estar perfeitamente em ordem. Ora, quando supomos um sistema de regras realmente existente e necessariamente acompanhando o uso significativo de sinais em nossa linguagem, as impressões veiculadas por essas frases ficam todas justificadas. Mas no momento em Wittgenstein traz essas expressões ao primeiro plano de sua investigação, seu objetivo é, por assim dizer, profilático: é preciso que o filósofo esteja atento contra essas imagens.

Tomemos a ideia de que, uma vez que estejamos de posse da regra correta, uma vez que compreendamos, por exemplo, a estrutura que organiza a sequência dos números naturais, então nós temos à mão toda a sequência (“de alguma maneira") presentificada até o infinito. Há, aqui, uma tendência em falar sobre a regra como um trilho que se estende infinitamente, mas do qual só vemos uma pequena porção. É para a origem dessa imagem compulsiva que Wittgenstein se dirige quando ele pergunta:

\footnotetext{
7“A regra determina o que eu devo escrever a cada etapa"

${ }^{8}$ O MS 124 data de pelo menos dois períodos distintos, o primeiro de 1941, o segundo de 1944. Mais de metade do manuscrito foi publicada como BGM VII. A passagem citada é quase que imediatamente posterior ao último trecho ali publicado (não pertencendo, portanto, a nenhuma obra publicada de Wittgenstein).

"“As passagens já estão todas feitas"

142
} 
De onde vem a ideia de que o começo da série é o pedaço visível de trilhos que se se estendem de modo invisível até o infinito? Bem, no lugar da regra nós poderíamos imaginar trilhos. E à aplicação não limitada da regra equivaleriam trilhos infinitamente longos. ${ }^{10}$ (PU \218)

Ora, aqui está posta para funcionar a máquina lógica que parece animar o funcionamento da linguagem. Parece que se seguimos essa metáfora entendemos melhor o que são regras: elas são como trilhos que compelem o movimento numa direção determinada. A partir de uma imagem como essa, o que fazemos é explicar a necessidade que encontramos em certos domínios da linguagem. A lógica deve cuidar da linguagem, e precisamente neste sentido: ela põe a linguagem nos trilhos. E em algum momento, tendemos a ir além da metáfora e dizemos: ela é o elemento fixo (inexorável), a estrutura sem a qual a fluidez do uso empírico da linguagem seria apenas dispersão de sinais. A lógica diz o que deve ser a linguagem, mas de um modo tal que parece não haver escolha mais. Assim fazemos justiça à concepção usual do que seja lógica, já que nesse campo (tanto quanto no campo da matemática) estamos falando em necessidades, e nos opomos a toda contingência e incerteza dos fatos. Analogamente, regras lógicas subjazem à linguagem. Nesse caso, os passos que se pretendem dar no interior da linguagem só podem ser trilhados se seguirem um caminho previamente dado. São regras o que determina esse caminho — é precisamente nesse sentido que dizemos: uma vez dadas as regras, todos os passos estão previamente dados (cf. PU $\int \$ 190$ e 238).

\footnotetext{
${ }^{10}$ No original: "Woher die Idee, es wäre die angefangene Reihe ein sichtbares Stück unsichtbar bis ins Unendliche gelegter Geleise? Nun, statt der Regel könnten wir uns Geleise denken. Und der nicht begrenzten Anwendung der Regel entsprechen unendlich lange Geleise".
} 
Essa é também uma maneira segundo a qual a força da necessidade lógica pode ser justificada. Nesse âmbito, Wittgenstein pensa sobretudo na inexorabilidade, na certeza e segurança com a qual se afirma a validade das inferências lógicas. Afinal de contas, o modo como a lógica relaciona proposições entre si parece exigir que haja uma estrutura que subjaz à passagem de uma proposição a outra, como se fosse evidente dizer: Ich darf ... nur folgern, was wirklich folgt! !1 (BGM I \8) - como se a inferência se movesse (segundo essa persistente metáfora) sobre trilhos postos pela lógica; ou, como Wittgenstein explica: "o que realmente segue" quer dizer: was die logische Mascbine wirklich hervorbringt ${ }^{12}$ (BGM I \$119). E o próximo passo é, mais uma vez, explicar a inexorabilidade da inferência lógica a partir de uma certa concepção do que ocorre por trás do ato de inferir, como se assim nós apontássemos para a casa de máquinas que move os fenômenos (cf. BGM I \$21). Quando ligamos dois pontos, diria Frege, a linha já está lá — mas de um modo especial, da maneira como apenas a lógica pode fazer: sublimemente, no Medium des Verstehens. E quando eu sigo, por exemplo, a regra "partindo do 0 , some 2 indefinidamente" tudo se passa como se a minha tarefa se reduzisse a traçar com linhas mais fortes os números que já estavam (de algum modo) escritos.

\footnotetext{
11 "Eu só posso derivar aquilo que realmente segue!"

12“"O que a máquina lógica efetivamente produz" 144
} 
3.

Wittgenstein chamou a afirmação "todos os passos já foram dados antes que eu agisse" de uma proposição simbólica. Ela nos oferece uma imagem - que não precisa ser recusada, mas que precisa ser compreendida para poder ser bem usada. Em especial, ele pretende ressaltar que a função dessa imagem é "destacar uma distinção entre condicionalidade causal e condicionalidade lógica" (PU \220) ${ }^{13}$. Mas esta é uma distinção sutil que pode nos levar a alguns mal entendidos. Para esclarecer a estranha expressão: "condicionalidade [Bedingtheit] lógica", examinaremos aquela à qual Wittgenstein a opõe: a condicionalidade empírica.

Parecia, num primeiro momento, que essas considerações deveriam indicar que "o que parece ser uma compulsão lógica, na verdade é apenas uma compulsão psicológica" — e aqui, no entanto, poder-se-ia perguntar: então eu conheço os dois tipos de compulsão?! ${ }^{14}$ (BGM I, \$118)

A condicionalidade causal é uma imagem mais presente, na medida em que essa é toda a determinação que vemos em meio aos fenômenos - como quando bolas de bilhar se tocam e dizemos "o movimento da primeira bola é a causa do movimento da segunda" e inferimos daí: "a primeira bola determina o movimento da segunda". E, de modo análogo, nós conhecemos determinações psicológicas (que são, também, determinações empíricas). Um sorvete é a causa do sabor, a luz e a matéria são a causa das minhas imagens visuais, uma navalha em minha pele é a causa da minha dor, sinapses são a

13 "er sollte einen Unterschied hervorheben zwischen kausaler Bedingtheit und logischer Bedingtheit"

${ }_{14}$ No original: "Es schien zuerst, als sollten diese Überlegungen zeigen, daß, 'was ein logischer Zwang zu sein scheint, in Wirklichkeit nur ein psychologischer ist' - und da fragte es sich doch: kenne ich also beide Arten des Zwanges?!" 
causa de minhas associações. E dizemos: cada um desses efeitos é determinado por sua causa (de acordo com certas leis naturais). Mas, para além da esfera da causalidade, nós conhecemos ainda um segundo tipo de determinação? Bem, o que sabemos é que nenhuma dessas conexões causais que mencionamos ao enumerar o que chamamos de "determinações causais" interessa à filosofia - principalmente porque elas não podem dar conta do que é querer dizer algo ou compreender algo ou ver algo como algo. E de modo mais relevante no presente contexto: elas tampouco podem dar conta do modo como nossas regras funcionam, já que estas não agem sobre nós como causas agem sobre efeitos. Justamente por isso nós dizemos: deve haver uma determinação não causal que seja a responsável por esses traços essenciais à linguagem (e não só à linguagem, mas às matemáticas e à cinemática, por exemplo) - esses que nos permitem falar do campo conceitual como algo distinto do empírico.

A inexorabilidade a partir da qual essas disciplinas que acabamos de mencionar operam deveria ser a evidência maior de que a determinação lógica é algo realmente existente. Diante dessa evidência, nossa tendência é responder à pergunta de Wittgenstein afirmando: é óbvio que nós conhecemos um tipo de compulsão não causal. E, exemplificando o que queremos dizer com isso, nós enumeraríamos: a lógica (a gramática) determina sentido; a cinemática determina a forma geral dos movimentos; a geometria determina as relações entre as formas etc. $\mathrm{O}$ que estamos querendo dizer em cada caso é que, analogamente ao que se passa no plano dos fenômenos (onde corpos compelem o movimento de outros corpos), nós somos compelidos (mas 146 
agora logicamente compelidos) a aceitar a relação entre certos princípios e certas formas a priori. A partir disso a resposta deve ser evidente: "Sim, nós conhecemos dois tipos de compulsão".

A partir do modo como fomos levados pela analogia entre compulsão lógica e psicológica, diríamos então: deve haver princípios compulsores, de modo que a regra seria aqui eine treibende Kraft (BGM IV \$51). Nós afirmamos tanto porque, como o Kant da primeira Crítica, temos diante de nós o fato do a priori. Nós lidamos diariamente com disciplinas que apresentam relações inexoráveis, que, nós supomos, são devidas à inexorabilidade dos princípios, das regras que constituem essas disciplinas. Mas o que é essa inexorabilidade que é o traço distintivo dessas nossas disciplinas apriorísticas? Notemos que essa pergunta é apenas uma retomada daquela pergunta inicial: o conhecimento que temos dela é algo realmente distinto daquilo que vemos acontecer no interior dos fenômenos? — de modo que possamos dizer: "há uma inexorabilidade lógica realmente distinta da empírica".

4.

Wittgenstein insiste no fato de que, quando observamos a aplicação de uma lei lógica (e como mais poderíamos ter acesso à inexorabilidade da lógica?), ela certamente não é nada distinto de nós (como a lógica parece exigir do a priori: que ele esteja terminantemente separado do que é a posteriori; aqui, a lógica, ali, os fatos), já que, Wittgenstein afirma (BGM I \$118), não é a lei (ou a regra) o que é inexorável: nós somos inexoráveis ao empregar essa lei. E a inexorabilidade da matemática não deriva de outra fonte que não os infindáveis exercícios e a impiedosa exatidão que exigimos de nossas crianças 
quando as ensinamos a contar (cf. BGM I \4). Nós somos inexoráveis ao ensiná-las. E os processos por meio dos quais infundimos nossa cultura em nossas crianças (e, com isso, perpetuamos a inexorabilidade da matemática) pertencem à história de nossa sociedade. Ora, isso certamente não é lógica. Estamos falando, aqui, da ação de homens vivendo em sociedade. Homens que, como uma questão de fato, fazem algumas de suas regras valerem de modo inexorável - como no caso da regra recursiva que "determina" a sequência dos números naturais: não admitimos exceções aqui; não admitimos que nossas crianças escrevam "5" depois de " 3 "; e temos maneiras especiais, empíricas, de fazer essas regras prevalecerem.

Mas será que Wittgenstein sugere aqui a conclusão de que não há, na verdade, necessidade ou inexorabilidade lógica? Como se tudo o que tivéssemos fossem "regras empíricas", algo que só podemos conhecer a partir dos fatos, e, na verdade, a partir da generalização de fatos, por indução? É evidente que não. É só nos concentrarmos no método de Wittgenstein para lembrarmos que ele não afirmaria isso. Ele não interferiria dessa maneira no sentido que nós atribuímos às nossas palavras, e, portanto, não negaria à lógica um atributo tão essencial quanto a necessidade. $\mathrm{E}$ talvez de forma mais relevante: Wittgenstein não é um empirista. Pelo contrário, boa parte de seu esforço é garantir um discurso não empírico que dê conta desses traços da linguagem que parecem não estar sujeitos à duração, à temporalidade, à causalidade - o "discurso gramatical" que caracteriza a prosa das Investigações Filosóficas. Na verdade, o que ele faz é pedir que reconsideremos as exigências que nós impúnhamos ao dever lógico. Mas é importante que, para isso, nós 148 
Giovane Rodrigues

entendamos bem o que pode ser a compulsão lógica e o que significa "conhecer" algo como uma compulsão lógica. Ele diz:

Pode-se dizer, contudo, que as leis de inferência nos compelem; a saber, no mesmo sentido que outras regras da sociedade humana. O funcionário em $(17)^{15}$ deve fazer assim; ele seria punido se inferisse de outra maneira. Quem infere de maneira diferente certamente entra em conflito com a sociedade, por exemplo; mas também com outras consequências práticas. ${ }^{16}$ (BGM I \$116)

A lógica nos diz o que fazer. Ela nos diz qual o modo correto de agir. Ela nos mostra quais regras devemos seguir se quisermos agir em conformidade com a nossa sociedade. É evidente que as proposições da lógica não são uma descrição do que as pessoas costumam fazer, ou do que a maioria das pessoas faz. A lógica não se deixa subsumir pela história natural dos homens (cf. BGM VI 『49). A função da lógica é, simplesmente, apresentar a maneira correta de agir (mas ela não diz por que isso é correto, nem como isso se tornou correto). Ela diz: assumindo $x$ e $y$, então você deve assumir z. Nossa sociedade faz assim, como essa regra de inferência sugere. E nós agimos assim — se quisermos. Ou melhor: se quisermos agir de acordo com as convenções assumidas por nossa sociedade. Nesse caso, quando diante de $x$ e $y$, nós aceitaremos z (e nosso comprometimento é tal que nós

15 Trata-se de uma referência a um momento anterior da Parte I das Observações sobre os Fundamentos da Matemática, que citamos: "Em um regulamento lê-se: 'todos os que são mais altos que 1,80 m devem ser admitidos na divisão...'. Um funcionário anuncia os nomes das pessoas e suas respectivas alturas. Um segundo os distribui nas divisões tal e tal. - 'Portanto fulano ficará na divisão ...'. Isso é inferir”. (BGM I §17)

${ }^{16}$ No original: "Man kann aber dennoch sagen, daß die Schlußgesetze uns zwingen; in dem Sinne nämlich, wie andere Gesetze in der menschliche Gesellschaft. Der Kanzlist wie in (17), тиß es so tun; er wäre bestraft worden, wenn er anders schlösse. Wer anders schließt, kommt allerdings in Konflikt z.B. mit der Gesellschaft; aber auch mit andern praktischen Folgen." 
não pensamos duas vezes antes de inferir §). É evidente, a partir de um caso como esse em que vemos a aplicação da lógica, que nada nos obriga a agir de acordo com essa regra. Ou seja: apenas se não atentarmos aos limites de uma analogia tão pervasiva e ubíqua quanto entre "compulsão física" e "compulsão lógica" iremos tropeçar diante da expressão "determinação lógica".

Ainda que nosso resultado seja negativo, ele é precioso: regras não me movem como um impulso físico poderia me mover, elas não me conduzem como trilhos conduzem vagões, elas não determinam minhas ações da maneira como leis físicas determinam movimentos, elas não estruturam minha linguagem da maneira como concreto e ferro estruturam um edifício. Eis, portanto, onde nosso resultado negativo nos deixou: partimos da ideia de uma determinação (ou compulsão ou condicionalidade) lógica; como gostaríamos de sugerir, a melhor maneira de nos reconciliarmos com essas expressões perigosas é tomar como ponto de chegada, mais uma vez, o conceito de normatividade.

5.

Quando falamos em "determinação lógica”, usamos essa expressão num sentido parecido com este: "os passos são determinados pela fórmula..." (PU \189; BGM I \1). Analisemos essa importante observação de Wittgenstein, impressa tanto nas Investigações e as Observaçoes. Podemos perguntar: "como a fórmula faz isso?" — ou melhor: "o que é, para uma fórmula, determinar algo?”. Quando Wittgenstein, a partir desse exemplo, assume a tarefa de esclarecer o uso da palavra "determinar" ele é bastante 150

Revista de Filosofia Moderna e Contemporânea

Brasília, nº 1, ano 1, 2013. 
cuidadoso ao notar: não é a fórmula o que determina — como se a fórmula pudesse conter em si todas as suas aplicações, como se compreender o que a fórmula quer dizer fosse ter dado todos os passos "num só golpe" (PU $\$ \$ 188$, 191, 194), mentalmente talvez. "Determinar" não é algo que a fórmula faz, e isso se mostra se temos clareza a respeito do que queremos dizer quando, por exemplo, falamos “a regra ' +3 ' determina completamente para esses homens qual passo deve ser dado de um número a outro". Isso pode ser dito também desta maneira: "esses homens foram treinados (adestrados) de um modo tal que todos eles dão o mesmo passo de um número a outro quando diante da regra ‘+3"'. E isso nós diremos em casos específicos. Nós o diríamos, Wittgenstein avisa, para distinguir esses homens de outros, homens que simplesmente não saberiam o que fazer com a expressão “+3”, ou para aqueles que agem de modo completamente diferente quando diante daquele sinal. E há ainda muitos outros casos em que podemos dizer que certa regra determina que certos números devam ser escritos numa determinada sequência. Nós dizemos, por exemplo: "a fórmula $y=x^{2}$ determina o valor de $y$ uma vez estando dado um certo $x$, enquanto que a fórmula $y \neq x^{2}$ não determina o valor de $y$ nas mesmas condições". Mas "determinar", em nenhum dos dois casos é uma ação da regra. E ainda assim: isso é exatamente o que chamamos de "determinação lógica".

Perguntamos, mais uma vez: como a fórmula faz isso, como ela determina? Bem, sabemos que a função da regra, nesse caso, é algo bastante diferente daquilo que vimos ser a "determinação" quando usávamos essa palavra como sinônimo de "compelir", "condicionar", "instaurar", "criar", "gerar" etc. — quando falávamos de determinações empíricas. Nos casos em 
que dizemos que "a fórmula... determina os passos a serem dados", estamos afirmando apenas que a fórmula nos serve como uma ferramenta para julgar se certas ações estão ou não de acordo com o que consideramos ser os passos corretos a serem dados quando diante dessa fórmula específica (ou: daquilo que chamamos de "os passos corretos"). E isso depende, mais do que da fórmula, do treinamento que as pessoas que a usam receberam, do contexto em que a fórmula lhes é apresentada e daquilo que eles querem fazer com ela. E então esse sinal passa a nos servir como uma ferramenta na execução dessas ações. Esse sinal tem um lugar especial no interior da prática desses homens: a função de lhes dizer o que fazer. Mas é evidente que quem determina que os passos sejam dados são os homens, não a fórmula.

A determinação lógica sobre a qual falamos quando tentamos explicar o funcionamento de uma regra (sua normatividade) não está infusa nos usos regulares e empíricos no interior dos quais a usamos como modelo. Como se uma maquinaria lógica permeasse, fundamentasse e possibilitasse esses usos. Tampouco a regra está posta num mundo à parte, o mundo etéreo das formas ou algo que o valha. $\mathrm{E}$, na verdade, é só porque cedemos muito facilmente às analogias sugeridas por nossos modos de expressão que supomos que sempre que falamos em determinação lógica algo deve determinar (afinal, pode parecer que para todo verbo bem aplicado há, de direito, um substantivo a que se aplica). E esse algo determinante deve ocupar um lugar (se não físico, etéreo). E, por analogia, nós deveríamos concluir que as regras lógicas devem estar presentes nas ações regradas, como se, do contrário, elas não pudessem ser o que chamamos de "ação regrada". Mas a regra não é nada disso — a regra não 152 
é algo. Não sendo algo, a regra não faz nada. Nós fazemos algo com ela na medida em que a apresentamos como um modelo (normativo) de conduta.

$\mathrm{E}$ isso serve para que concluamos: se quisermos falar em "determinação" aqui, se quisermos continuar usando a expressão "determinação lógica", seria aconselhável que nos livrássemos da ideia de que ela pode ser usada em analogia à ideia de determinação causal. Como se a lógica fosse semelhante a um mecanismo, mas que opera de modo ideal, a partir de uma supra-causalidade, determinando a forma de nossas ações, inspirando-lhes as regras que, só elas, poderiam the conferir sentido. Como se as regras lógicas fossem um tipo de força motriz do sentido (à semelhança do modo como corpos transmitem força a outros corpos). Em oposição a isso, retornamos às trivialidades da qual partimos — à linguagem ordinária: regras são prescrições. Sua normatividade reside apenas no fato de que elas se nos afiguram como sinais que, por qualquer motivo que seja, nós em geral julgamos dever obedecer.

Referências bibliográficas

WITTGENSTEIN, Ludwig. Lectures on the Foundations of Mathematics, Cambridge 1939. From the Notes of R.G. Bosanquet, Norman Malcolm, Rush Rhees, and Yorick Smithies. Ed. by Cora Diamond. Chicago: The University of Chicago Press, 1984. (Primeira edição: 1976). 
. Bemerkungen über die Grundlagen der Mathematik. Werkausgabe Band 6. Frankfurt am Main: Suhrkamp Verlag, 1984. (Primeira Edição: Oxford: Blackwell, 1956).

- Philosophische Untersuchungen. Auf der Grundlage der Kritischgenetischen Edition neu herausgegeben von Joachim Schulte. Frankfurt am Main: Suhrkamp Verlag, 2003. (Primeira Edição: Oxford: Blakwell Publishing, 1953). 